\title{
Need for Nutrition Education in Health Professional Programs: A Review of the Literature
}

Nava Livne

Rosalind Franklin University of Medicine and Science, nava.livne@gmail.com

Follow this and additional works at: https://nsuworks.nova.edu/ijahsp

Part of the Medicine and Health Sciences Commons

\section{Recommended Citation}

Livne N. Need for Nutrition Education in Health Professional Programs: A Review of the Literature. The Internet Journal of Allied Health Sciences and Practice. 2019 Jan 01;17(1), Article 5.

This Article Review is brought to you for free and open access by the College of Health Care Sciences at NSUWorks. It has been accepted for inclusion in Internet Journal of Allied Health Sciences and Practice by an authorized editor of NSUWorks. For more information, please contact nsuworks@nova.edu. 


\title{
Need for Nutrition Education in Health Professional Programs: A Review of the Literature
}

\begin{abstract}
Purpose: The ever-increasing burden of obesity as a high risk factor for nutrition-related diseases, together with health professionals' lack of competencies in nutrition, has left health professional students needing further education to offer nutrition advising to patients. The purpose of this review was to summarize the current literature related to nutrition education in health professional programs.

Method: This literature review was conducted using eight scientific literature databases: PubMed, CINAHL Complete, PsycINFO, Academic Search Complete, Directory of Open Access Journals, Professional Development Collection, Complementary Index, and Google Scholar. Articles published in English from January 2007 through January 2018 were reviewed. Keywords and terms from the Medical Subject Headings [MeSH] thesaurus were used to create combinations of keywords. Of 128 articles that resulted from this search, 55 were chosen for the review.

Results: The findings revealed deficiencies in nutrition competency among health professional students. Students reported lacking adequate nutrition knowledge, basic counseling skills, and confidence to offer nutrition advice to patients. Lack of nutrition knowledge and counseling skills was inversely linked to profession-specific nutrition competencies that could lead to improved patient outcomes. Limitations of nutrition education across several programs were also unveiled. Nutrition interventions enhanced the achievement of Interprofessional Education Collaborative competencies, appreciation of one another's roles and responsibilities, interprofessional communication skills, and teamwork. The findings suggested that improving students' nutrition knowledge may result in improved patient outcomes.

Conclusions: Nutrition was viewed as a unifying topic-of-interest across health professional programs that increased students' knowledge and efficacy in providing basic nutrition counseling. Interprofessional nutrition education was regarded as a strategy to surmount the existing limitations of nutrition education and train students to tackle nutrition-related risk factors and prevent nutrition-related diseases.
\end{abstract}

\section{Author Bio(s)}

The author is a Ph.D. student in Interprofessional Health Studies at Rosalind Franklin University of Medicine and Science in North Chicago, IL. She earned a Ph.D. in educational psychology at Tel Aviv University in Israel and an MS in nutrition education at Rosalind Franklin University of Medicine and Science.

\section{Acknowledgements}

Acknowledgement Th author wishes to thank Dr. DiMaria-Ghalili of Drexel University (Philadelphia, PA) for her guidance and support in researching and writing this manuscript. 


\title{
IIJAHSP \\ The Internet Joưnal of Allied Health Sciences and Practice \\ Dedicated to allied health professional practice and education
}

Vol. 17 No. 1 ISSN 1540-580X

\section{Need for Nutrition Education in Health Professional Programs: A Review of the Literature}

\author{
Nava Livne \\ Rosalind Franklin University of Medicine and Science
}

United States

\begin{abstract}
Purpose: The ever-increasing burden of obesity as a high risk factor for nutrition-related diseases, together with health professionals' lack of competencies in nutrition, has left health professional students needing further education to offer nutrition advising to patients. The purpose of this review was to summarize the current literature related to nutrition education in health professional programs. Method: This literature review was conducted using eight scientific literature databases: PubMed, CINAHL Complete, PsycINFO, Academic Search Complete, Directory of Open Access Journals, Professional Development Collection, Complementary Index, and Google Scholar. Articles published in English from January 2007 through January 2018 were reviewed. Keywords and terms from the Medical Subject Headings [MeSH] thesaurus were used to create combinations of keywords. Of 128 articles that resulted from this search, 55 were chosen for the review. Results: The findings revealed deficiencies in nutrition competency among health professional students. Students reported lacking adequate nutrition knowledge, basic counseling skills, and confidence to offer nutrition advice to patients. Lack of nutrition knowledge and counseling skills was inversely linked to profession-specific nutrition competencies that could lead to improved patient outcomes. Limitations of nutrition education across several programs were also unveiled. Nutrition interventions enhanced the achievement of interprofessional education collaborative competencies, appreciation of one another's roles and responsibilities, interprofessional communication skills, and teamwork. The findings suggested that improving students' nutrition knowledge may result in improved patient outcomes. Conclusions: Nutrition was viewed as a unifying topic-of-interest across health professional programs that increased students' knowledge and efficacy in providing basic nutrition counseling. Interprofessional nutrition education was regarded as a strategy to surmount the existing limitations of nutrition education and train students to tackle nutrition-related risk factors and prevent nutritionrelated diseases.
\end{abstract}

Keywords: Nutrition education, profession-specific nutrition deficiencies, nutrition education limitations, interprofessional nutrition competencies 


\section{INTRODUCTION}

The prevalence of obesity in American adults has increased during the past five years and today is at an all-time high. In 2015$2016,39.8 \%$ of U.S. adults aged 20 and over were diagnosed as obese with a body mass index [BMI] of $\geq 30$, while $35 \%$ were overweight. ${ }^{1}$ The obesity rate among adults aged 40 to 59 was $42.8 \%$, a disturbing percentage compared to $41.0 \%$ of obese adults aged 60 or older, and $35.7 \%$ of obese younger adults aged 20 to 39 . These data showed a persistent increase in the incidence of obesity when compared to $37.9 \%$ of obese adults aged 20 years and older, and $32.8 \%$ who were classified as overweight in 2013$2014 .{ }^{2}$ The obesity prevalence among children and adolescents was also staggering. Data showed that in $2016,18.4 \%$ to $20.6 \%$ of children aged 6 to 19 years and $9.4 \%$ of toddlers aged 2 to 5 years were obese, based on a BMl of equal or greater than the $95^{\text {th }}$ percentile matched for their age and gender. ${ }^{1,3}$ Moreover, $31.3 \%$ of children aged 10 to 17 years and $14 \%$ of toddlers aged 2 to 5 years were overweight, based on a BMl of equal or greater than the $85^{\text {th }}$ percentile and less than the $95^{\text {th }}$ percentile matched for their age and gender. ${ }^{3}$

Although other diseases can also result from poor nutrition and lack of nutrition education, (for example, liver disease), early and adult obesity, and being overweight are the primary risk factors that increase the incidence of chronic nutrition-related diseases in American adults. ${ }^{4}$ Obesity is strongly associated with an increase in cardiovascular diseases (CVD) and ischemic stroke, while weight loss leads to a significant reduction in risk for these diseases. ${ }^{5}$ Obesity is also a major risk for type 2 diabetes (T2D), and trends in the incidence of T2D have closely mirrored those of obesity. ${ }^{6}$ Menke et al found that T2D increased by $18.00 \%$ to $20.00 \%$ among those who were obese. ${ }^{6}$ The International Agency for Research on Cancer found that visceral adiposity and obesity are strongly associated with certain types of cancer, for example, colorectal, esophageal, postmenopausal breast, melanoma, and less common malignancies. ${ }^{7}$ Obesity is also related to increased risk of osteoporosis (lower bone density). Beck et al showed that there was a significantly greater incidence of lower-extremity fractures in obese women. ${ }^{8}$ Unfortunately, obesity is also linked to tooth decay and dental caries. Children and adolescent obesity is significantly associated with high amount of sugars intake and dietary acids in beverages which lead to periodontal disease and teeth erosion. ${ }^{9}$ In $2013-2014,50 \%$ of adults had one or more preventable nutrition-related chronic diseases as a result of poor nutrition, and more than $50 \%$ of adult morbidity and premature mortality resulted from similar behavioral determinants. 6,10 These findings suggest that obesity is a high risk factor for nutrition-related diseases that may result from poor nutrition and lack of nutrition education.

The annual medical costs for individuals with chronic obesity-related diseases have also increased. In $2014,86 \%$ of the nation's $\$ 2.7$ trillion annual health care expenditures were for people with chronic health conditions. ${ }^{11}$ The medical cost related to obesity ranged from $\$ 147$ billion to $\$ 210$ billion per year. This was a record high, implying a growing demand for more healthcare providers. ${ }^{12}$ In 2008 , the annual medical costs for obese individuals were $\$ 1,429$ higher than those for people with normal weight. ${ }^{10}$ Thus, health professionals have been confronted with many patients who need to modify their diet as part of their disease management. ${ }^{13}$ In practice, health professionals not only held biases against obese individuals but were also ill-prepared to address obesity-related diseases. With the increasing obesity epidemic and health professionals' lack of nutrition competencies to address obesity, the need for nutrition education in health professional programs has become imperative. ${ }^{13}$ The purpose of this review was to summarize the current literature related to nutrition education in health professional programs.

\section{METHODS}

\section{Search Strategy}

A search strategy was implemented to find the most pertinent, evidence-based peer-reviewed articles on the effect of nutrition education in preparing health professional students to provide nutritional advice to patient. Eight scientific literature databases were searched: PubMed and its primary MEDLINE sub-database, CINAHL Complete, PsycINFO, Academic Search Complete, Directory of Open Access Journals, Professional Development Collection, Complementary Index, and Google Scholar. Articles published in English from January 2007 through January 2018 were searched, unless the articles had been cited as secondary sources in earlier years or had been either peer-reviewed studies or systematic reviews. Keywords or terms were chosen from the Medical Subject Headings [MeSH] thesaurus. The conventional Boolean operators, AND/OR, were used to create combinations of keywords that narrowed or broadened the search.

Six keyword combinations were used for the proposed research: 1. (nutrition knowledge OR attitudes OR confidence) AND (health professional students); 2 . (nutrition OR dietary counseling OR advice OR nutrition competencies) AND (health professional students OR graduates); 3. (nutrition education OR nutrition course) AND (health professional programs) AND (physician assistant OR physical therapist OR nurse OR pharmacist students); 4. (nutrition education OR intervention) AND (nutrition competencies) AND (health professional students); 5. (nutrition education OR nutrition course) AND (health professional programs) OR (interdisciplinary OR interprofessional collaboration learning); and 6. (nutrition education effectiveness OR influence OR impact) AND (attitudes OR confidence OR practice) AND (health professional programs OR students). 
Together, 190 articles were initially identified across the eight databases, including articles found in citations. Of them, studies were chosen only if they met the initial inclusion criteria, resulting in 59 articles in PubMed, 43 articles in CINAHL, four articles in PsycINFO, two in Academic Search Complete, five in Directory of Open Access, three in Complementary Index, and 24 articles in Google Scholar.

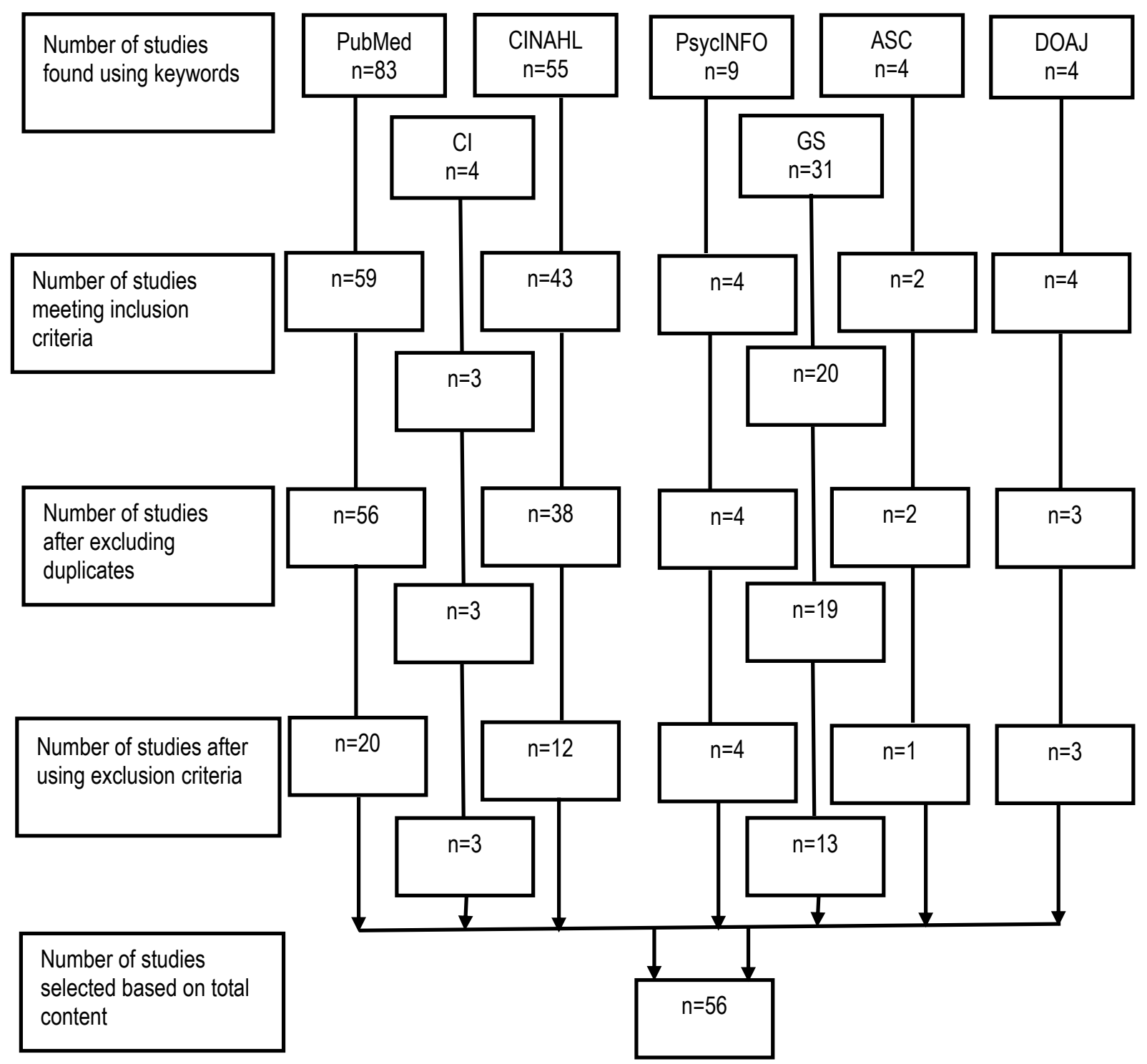

Figure 1. Flow of Review Process and Study Selection

Inclusion criteria were as follows: 1) articles published in January 2007 through April 2017, unless they were cited as promoting advances in nutrition education and published earlier; 2) peer-reviewed articles, systematic reviews, or evidence-based research articles; 3) articles reported on findings in the US; 4) experimental designs, including randomized controlled pretest-posttest experiments, observational studies, or self-report surveys; 5) participants were graduate students in interprofessional (IP) health professions or other healthcare students and providers, who were involved in nutrition counseling or advice; 6) samples included at least 25 participants; and 7) outcome measures were related to nutrition knowledge, attitudes, or behavioral changes in nutrition advising.

Exclusion criteria were as follows: 1) articles published in 2006 or earlier; 2) articles that reported results outside the US, unless they were cited as contributing to nutrition or inter professional (IP) education in the US; 3 ) full textbook chapters and policy papers, as they did not discuss evidenced-based findings; 4) clinical trials, nutrition therapy, and prognosis articles that were not relevant to nutrition education; 5) students from schools of medicine and dietetics programs unless they participated in team-based activities 
(medical students receive nutrition education within their curriculum, while dietetic students major in nutrition education); 6) undergraduate college or university students from non-health professions; 7$)$ small samples $(n<25)$ and case studies; 8 ) outcome measures not linked to changes in knowledge and attitudes toward nutrition; and 9) practicing clinicians. Together, 125 articles were chosen for the current article, of which 56 directly related to students and nutrition education in health professional programs. Figure 1 illustrates the review process and study selection.

\section{RESULTS}

\section{Nutrition Competency Deficiencies in Health Professional Students}

Despite the need for nutrition education, there was a noticeable decline in the availability of nutrition courses in health professional programs. Bergerson et al found that of 50 pharmacy schools, only $6 \%(n=3)$ offered a required nutrition course while $4 \%(n=2)$ offered an elective course in nutrition. ${ }^{14} \mathrm{Not}$ all health professional programs included a required nutrition course in their curricula. Schoettler et al observed that nutrition education was unavailable to health professional students, leaving them lacking adequate knowledge of nutrition. ${ }^{15}$

When nutrition courses were available, the number of hours dedicated to nutrition education dropped to less than 20 hours of nutrition education over the past 25 years. In his 1999 survey, Sacks reported that $90 \%(n=98)$ of health profession schools offered 18 hours of nutrition education over their programs. ${ }^{16}$ This number has slightly changed to 19.6 hours of nutrition education in the most recent survey conducted in 2010. This negligible change in nutrition education did not meet the minimum of 25-30 nutrition education hours recommended by the National Research Council Committee on Nutrition in Medical Education ${ }^{17}$ as today's gold standard in nutrition education for health professionals. ${ }^{17}$ Weiner et al reported that 37 to 44 hours were recommended for nutrition education to health profession schools, as agreed by curriculum administrators and nutrition educators. By either standard, health professional programs fell short of offering adequate nutrition education and nutrition competencies.

The term "competency" is defined as a component within the larger domain of providing high value care to improve patient outcomes. ${ }^{19}$ Competencies can be formulated as learning objectives and learning activities at the pre-licensure level, allowing flexibility for health educators to develop profession-specific curricula to prepare students for practice. ${ }^{20}$ For each health profession, specific competencies should be translated into specific learning outcomes and evaluation methods per course. ${ }^{19}$ Accordingly, professional competencies of practice related to nutrition care and interventions will be different and specific to profession-specific practice.

However, current nutrition education has been regarded as outdated and lacks the dynamics to continually adjust its content to meet the changing needs of health education training..$^{21}$ Chang et al found that current pharmacy professional programs lacked basic nutrition courses and left students with insufficient knowledge to provide nutrition advice for the prevention of chronic diseases..$^{22}$ Thomas et al found that the structure of nutrition courses was fragmented and focused only on basic nutrition concepts, producing graduates who lacked nutritional competencies to improve patient outcomes. ${ }^{23,24}$

In response to the Institute of Medicine's call to include all health professionals in team-based care and health services, the research focused on nutrition education in health professional programs. ${ }^{25}$ Evidence indicated that general practitioners, nurse practitioners, dietitians, naturopaths, and exercise physiologists perceived nutrition counseling and nutrition care as superficial and ineffective because of inadequate nutrition education and low prioritization of nutrition care in their pre-clinical education. ${ }^{26}$ Nutrition education in nursing, pharmacy, dentistry, and dental hygiene programs showed a consistent inadequacy of nutrition education and lack of nutrition learning and counseling experiences in these programs. ${ }^{27,28}$

The author of this review extracted from the chosen studies everything that was reported about deficiencies in nutrition education among students in the physician assistant, physical therapy, pharmacy, nursing, and dentistry programs. Favia et al found that the physician assistant program at Midwestern University, IL, did not provide adequate nutrition education. ${ }^{29} \mathrm{As}$ a result, students and graduates developed unfavorable attitudes toward nutrition and were unable to demonstrate nutrition knowledge and counseling skills for accreditation. Students, in turn, believed that more nutrition education should have been integrated into their courses. ${ }^{29}$ Similarly, $50 \%(n=48)$ of physician assistant students at East Carolina University, NC, could not prescribe tube feeding or counsel patients on modified diets; in addition, they demonstrated negative attitudes toward nutrition. ${ }^{30}$ The consequences of inadequate nutrition education were carried over to physician assistant graduates. Demory-Luce and McPherson reported that most physician assistant graduates in Texas were dissatisfied with the nutrition education they had received and felt they were inadequately trained to offer nutrition advice. ${ }^{31}$ Despite the paucity of their evidence, these findings showed that students failed to meet the accreditation requirements of basic counseling and patient education to adopt healthful diet and lifestyle patterns, pointing to the need for reexamining nutrition education in physician assistant programs in the U.S. ${ }^{32}$ 
The American Physical Therapist Association ${ }^{33}$ has viewed nutrition counseling as part of the practice scope of physical therapists and argued that it was their duty to attend to patients' nutritional needs. ${ }^{33}$ While physical therapists can successfully treat musculoskeletal conditions, nutrition is largely missing from physical therapist education and patient care. ${ }^{34}$ Morris et al developed strategies to perform screening for and identification of health problems related to nutrition deficits and strategies for providing physical therapy-related nutrition management by physical therapy graduates who lacked the college and skills to provide dietary advice to patients. ${ }^{35}$ Nelson et al showed that $78.1 \%(n=117)$ of physical therapy students at Wichita State University, KS, reported having received inadequate nutrition education and had pursued information and knowledge about nutrition through the media. ${ }^{36}$ Only $36.4 \%(n=55)$ of them reported receiving nutrition education through their formal physical therapy education. Similarly, 48 physical therapy students at East Carolina University, NC, failed to identify and screen alcohol consumption as indicated by $77 \%$ incorrect responses on a nutrition knowledge survey. ${ }^{23}$ These findings indicated that physical therapy students in these programs failed to understand basic nutrition concepts and psychological aspects associated with diet-related diseases and basic nutrition counseling skills; this highlights the need to review or revise the curricula of nutrition education in physical therapy programs. ${ }^{36,37}$

Pharmacists should also have basic knowledge and understanding of nutrition to educate the public about nutrition, prevention of drug-food interactions, and their potential impact on patient health. ${ }^{38}$ Evidence showed that $49 \%(n=33)$ of doctor of pharmacy students at Butler University, IN, believed that nutrition counseling on diet modification was their professional responsibility, but $71 \%(n=48)$ of them lacked the skills and confidence to induce behavioral dietary changes in patients. ${ }^{39}$ In another study at Butler University, $1^{\text {st }}$-, 2 ${ }^{\text {nd }}$, and $3^{\text {rd }-y e a r ~ p h a r m a c y ~ s t u d e n t s ~ d e m o n s t r a t e d ~ a ~ d e c r e a s e d ~ c o m f o r t ~ l e v e l ~ i n ~ c o u n s e l i n g ~ p a t i e n t s ~ a b o u t ~ d i e t ~}$ when faced with patients with higher BMls. ${ }^{40}$ Chang et al found that 25 pharmacy students at the University of Illinois at Chicago had difficulty understanding basic nutrition (for example, how to translate the required daily calories into daily amounts of carbohydrate, fat, and protein into the make-up of a meal). ${ }^{22}$ These studies suggested that pharmacy students failed to calculate patient-specific nutritional and drug dosing/delivery requirements, while others failed to provide nutrition counseling on diet, nonprescription-drug products, and dietary supplements to patients, all of which intended to enhance patient outcomes. ${ }^{41}$ Together, the findings implied that pharmacy programs might need to be reviewed.

Nursing students in the U.S. also lacked nutrition knowledge. For example, $43 \%(n=99)$ of nursing students at Drexel University, PA, were unable to identify the carbohydrate content of $4 \mathrm{oz}$. of orange juice. Fifty percent $(n=101)$ of the students were not aware that carbohydrate content is listed as "total carbohydrate" on food labels. ${ }^{42}$ Seventy-seven percent $(n=42)$ of nursing students at East Carolina University, NC, failed to identify dietary sources of cholesterol as manifested by $77 \%$ incorrect responses. Students demonstrated lack of basic knowledge related to obesity as measured by a mean score of 2.4 out of 4.0 on a knowledge survey. Additionally, $36 \%(n=20)$ of them lacked the ability to educate patients on dietary intake. ${ }^{23}$ Touger-Decker et al reported that $45 \%$ $(n=68)$ of nurse practitioner students did not know how to perform tube feeding or prescribe a modified diet. ${ }^{30}$ The findings indicated that nursing students were deficient in providing clinical and community preventive services, including nutrition education, counseling, and other lifestyle programs for patients and communities, pointing toward the need to improve nursing nutrition education to preserve healthy patient outcomes. ${ }^{43}$

Seventy percent $(n=30)$ of dental students at a southeastern university did not know how to prescribe a modified diet, and $99 \%$ $(n=42)$ of them failed to prescribe tube feeding orders. ${ }^{23} \mathrm{~A}$ group of 74 dental students from three well-known universities exhibited inconsistencies in providing dietary advice to patients because they had insufficient nutrition knowledge. ${ }^{44}$ Although the students demonstrated knowledge in certain nutrition areas, they were mainly concerned with oral health problems such as acid erosion, and ignored general nutrition-related problems of obesity and nutrition-related diseases. Sixty-six percent $(n=49)$ of them felt that they had received insufficient nutrition education in dietary management of patients because of limited nutrition education hours. ${ }^{44}$ Twenty-five dental hygiene students at Eastern Washington University, WA, could not identify nutrition-related oral manifestations of menopause. Likewise, they failed to provide menopause-related dietary advice, such as limited intake of sodium, caffeine, and alcohol due to a lack of nutrition knowledge. ${ }^{45,46}$ These studies suggested that dental and dental hygiene students failed to meet their program's competencies of performing oral screening, oral assessment, and nutrition counseling to direct health promotion, disease prevention, and improvement of patient outcomes. ${ }^{47}$ Together, these findings indicated serious profession-specific deficiencies in nutrition knowledge and nutrition competencies for patient management across health professional students. Table 1 summarizes professions-specific nutrition deficiencies and the corresponding nutrition competencies across five health professional students. 
Table 1. Profession-Specific Nutrition Deficiencies Versus Nutrition Competencies Across Health Professional Students

\begin{tabular}{|c|c|c|}
\hline Profession-specific students & Nutrition deficiencies & $\begin{array}{c}\text { Nutrition competencies for patient } \\
\text { management }\end{array}$ \\
\hline Physician Assistant 32 & $\begin{array}{l}\text { Lack of nutrition knowledge } \\
\text { - Tube-feeding prescription } \\
\text { Lack of counseling skills on modified } \\
\text { diet } \\
\text { Negative attitudes toward nutrition }\end{array}$ & $\begin{array}{l}\text { Patient education about a modified diet } \\
\text { and healthy food intake } \\
\text { Counseling skills related to nutrition } \\
\text { Tube-feeding prescription with } \\
\text { medication and diagnostic tests } \\
\text { related to nutrition therapy } \\
\text { (specialty) }\end{array}$ \\
\hline Physical Therapy ${ }^{37}$ & $\begin{array}{l}\text { Lack of nutrition knowledge } \\
\text { - Nutrition screening, e.g., alcohol } \\
\text { consumption } \\
\text { - Identifying nutrition deficits, e.g., } \\
\text { macronutrients, vitamins } \\
\text { Lack of counseling skills on dietary } \\
\text { intake } \\
\text { Knowledge acquisition from incredible } \\
\text { sources }\end{array}$ & $\begin{array}{l}\text { Knowledge of evidenced-based basic } \\
\text { nutrition concepts associated with } \\
\text { diet-related diseases } \\
\text { Nutrition screening for referrals to other } \\
\text { healthcare professionals, e.g., } \\
\text { registered dietitian. } \\
\text { Basic nutrition counseling skills }\end{array}$ \\
\hline Pharmacy ${ }^{41}$ & $\begin{array}{l}\text { Lack of basic nutrition knowledge } \\
\text { - Translation of required daily } \\
\text { calories into carbohydrates, fat, } \\
\text { protein in a meal } \\
\text { Lack of nutrition counseling skills } \\
\text { Lack of confidence to counsel patients }\end{array}$ & $\begin{array}{l}\text { Patient education on dietary intake } \\
\text { - } \quad \text { Calculation of patient-specific } \\
\text { nutritional and drug dosing/delivery } \\
\text { requirements } \\
\text { - } \quad \text { Parenteral nutrition therapy in } \\
\text { some programs counseling skills } \\
\text { - } \quad \text { Modified diet } \\
\text { - } \quad \text { Don-prescription drug products } \\
\text { - } \quad \text { Evidence-basy supplements } \\
\text { recommendations to healthcare } \\
\text { providers, or when appropriate, the } \\
\text { public }\end{array}$ \\
\hline Nursing ${ }^{43}$ & $\begin{array}{ll}\text { Lack of nutrition knowledge } \\
\text { - } \quad \text { Macronutrient content in foods } \\
\text { - } \quad \text { Sources of cholesterol } \\
\text { - } \quad \text { Obesity risk factors } \\
\text { - } \quad \text { Understanding food labels } \\
\text { - } \quad \text { Tube-feeding procedures } \\
\text { - } \quad \text { Modified diet prescription } \\
\text { Patient education on dietary intake }\end{array}$ & $\begin{array}{l}\text { Nutrition education as a preventive } \\
\text { service } \\
\text { - Patient } \\
\text { - Communities } \\
\text { - Tube feeding and medications } \\
\text { administration via a nasogastric, } \\
\text { orogastric or gastrostomy tube } \\
\text { Patient education and counseling skills } \\
\text { related to nutrition }\end{array}$ \\
\hline Dental/Dental hygiene ${ }^{47}$ & $\begin{array}{l}\text { Insufficient nutrition knowledge } \\
\text { - } \quad \text { Tube feeding orders } \\
\text { - } \quad \text { Nutrition-related oral } \\
\text { manifestations }\end{array}$ & $\begin{array}{l}\text { Oral screening } \\
\text { Oral assessment } \\
\text { - Nutrition risk factors } \\
\text { - Risk factors for dysphagia persons } \\
\text { with nasogastric tube feeding }{ }^{41} \\
\text { Nutrition education on modified dietary } \\
\text { intake } \\
\text { Counseling skills on health promotion } \\
\text { and disease prevention }\end{array}$ \\
\hline
\end{tabular}

Table 1 unveils both similarities of nutrition deficiencies among students across health professions -- lack of nutrition knowledge and counseling skills on dietary intake and differences in profession-specific nutrition deficiencies. For example, physician assistant and dental students could not prescribe nutritional tube-feed orders. Nursing students failed to administer tube-feeding, and 
pharmacy students failed to translate required daily calories into macronutrients in a meal. Comparable similarities and differences are observed in profession-specific nutrition competencies for patient management. Health professional students must possess the ability to educate patients about nutrition and demonstrate counseling skills across professions. Still, not all health professional students are expected to give in-depth dietary advice. Physical therapy students must demonstrate nutrition screening for referrals vs. dentist and dental hygiene students who must perform oral assessment to provide a proper treatment. Similarly, pharmacy students must calculate patient-specific nutritional and drug dosing/delivery.

Table 1 also reveals that a lack of nutrition knowledge and counseling skills is inversely linked to profession-specific nutrition competencies. The stronger the extent of nutrition deficiencies of students, the less likely they would be able to achieve their profession-specific nutrition competencies. As nutrition competencies aim to improve patient outcomes, one could deduce that enhancement of student nutrition knowledge and counseling skills is indirectly associated with patient outcomes. Nutrition knowledge and skills of health students correlate with acquisition of nutrition competencies. The latter lead to improved patient outcomes. This implication was confirmed by Malone and Alger-Mayer, who showed that 59 overweight patients $\left(\mathrm{BMl}>27 \mathrm{~kg} / \mathrm{m}^{2}\right)$ experienced an average of $4.8 \%$ body loss following a 20 -week nutrition education program provided by pharmacists. ${ }^{48}$ Jordan and Harmon also found that 12 patients who participated in 15-minute visits over six months, each focusing on diet, exercise, and nutrition, significantly decreased their body weight, visceral fat, waist circumference, and BMI when compared to baseline. ${ }^{49}$ Marples et al reviewed 24 studies and found that nutrition training for health care students and staff improved their nutrition knowledge and clinical practice, concluding that nutrition knowledge was linked to improved patient nutritional intake and outcomes. ${ }^{50}$ Together, these findings implied that improving student nutrition knowledge and counseling skills may lead to improved patient outcomes.

In summary, health professional students should acquire profession-specific nutrition competencies, each intended to manage a patient's condition from different aspects, as illustrated in Table 1 and in the two paragraphs that follow. In that way, students will be empowered to work together as teams to improve patient outcome.

\section{Limitations of Nutrition Education in Health Professional Programs}

Evidence suggested that deficiencies in nutrition knowledge and nutrition competencies of health professional students were a result of an inadequate amount of nutrition education. Nelson et al found that of 33 physical therapy programs, only one program offered a formal, dedicated nutrition course, for a total of 10 total class hours. ${ }^{36}$ Similarly, $46 \%$ of pharmacy schools offered an elective nutrition course while only $19 \%$ of them had a dedicated nutrition course as part of their curriculum. ${ }^{51}$ In 2011 , there was an average of 15.9 hours of didactic nutrition taught in 24 U.S. dental schools and no clinical hours reported. ${ }^{28}$ Touger-Decker showed that over the past 25 years, the number of nutrition education hours for dental students remained constant, with 16 class hours on average, despite growing evidence of the essential role of nutrition in oral diseases. ${ }^{21}$ Other programs offered integrated nutrition instruction in curriculum-based courses, with an average of 5 class hours. ${ }^{21}$ From the small number of hours devoted to nutrition, one could deduce that limited nutrition information, which was integrated into existing curricula, might be insufficient and superficial. In sum, the benefits of integrated vs. a dedicated nutrition education remain unclear and might need to be investigated.

Touger-Decker et al also revealed specific nutrition topics in which health professional students were deficient, such as performing nutrition screening, prescribing tube feeding, ordering parenteral nutrition, and counseling patients on modified diets. ${ }^{30}$ PeñaPurcell et al surveyed nutrition and health faculties to determine the strengths, needs, and gaps in nutrition and health programs at Extension Universities nationwide. ${ }^{52}$ The results showed that $48 \%(n=57)$ of the programs conducted a systematic review of their nutrition curriculum, helping faculty identify areas for improvement in specific nutrition topics, such as knowledge of the Dietary Guidelines for Americans and food management. From the reported deficiencies of students in basic nutrition competencies, one could deduce that nutrition education might have some didactic limitations, including relevant nutrition topics that had not been covered in health professional programs. Whether or not faculty members could remedy these limitations has not yet been explored. ${ }^{21,42,47}$

Lack of communication skills was another topic in which health professional students were not well trained. Lenders et al reported that health professional students demonstrated poor communication and lacked collaborative skills due to ineffective nutrition education. ${ }^{53}$ Poor teamwork posed an additional barrier to preparing health professional students to deliver high quality-of-care and improve patient outcomes. ${ }^{13}$ Health professional students also reported a lack of confidence in giving dietary advice because of inadequate nutrition communication and counseling skills. ${ }^{39,53}$ This evidence suggests that students might have difficulty meeting the program's accreditation standards for nutrition education and may encounter difficulties entering the health professional workforce as a holistic practitioner. Overall, students' deficiencies in nutrition competencies, along with insufficient nutrition education, highlight the need for nutrition education in health professional programs for preventing and improving patient care of nutrition-related chronic diseases. However, new indications have suggested promising ways to improve the nutrition competencies of students in health professional programs. 


\section{A Paradigm for Boosting the Nutrition Competencies of Health Professional Students}

Emerging evidence confirms that nutrition intervention could improve the nutrition knowledge, attitudes, and skills of health professional students. Twenty-five $2^{\text {nd }}$ - and $3^{\text {rd }}$-year pharmacy students at the University of Illinois at Chicago, IL, increased their confidence in giving dietary advice to patients after completing a 2-credit-hour elective course in clinical nutrition. ${ }^{22}$ Using a pretestposttest design, the results showed that students strengthened their self-efficacy significantly, as indicated by the differences between their pretest and posttest measures. Working in teams of five students, students learned to speak confidently at the point of care about the role of nutrition in preventing chronic diseases while evaluating, synthesizing, and applying the knowledge they had acquired. The authors argued that team-based nutrition education could boost pharmacy students' confidence in providing nutrition advice to the public. 22

Likewise, 78 doctoral pharmacy students at Butler University, IN, had participated in a 3-week nutrition intervention that focused on the pharmacist's role in nutrition counseling. ${ }^{39}$ On completion of the intervention, students increased the awareness of their responsibility to educate patients about diet and health-related behaviors. Students not only expressed their willingness to educate patients about diet modification but were also ready to help patients manage their weight and change their dietary behaviors. The authors concluded that nutrition intervention encouraged pharmacy students to educate the public about nutrition and a healthy diet. 39

Moreover, 14 osteopathic medical students and 16 pharmacy students at Midwestern University, IL, attended a 1.5-credit hour course on nutrition and lifestyle modifications. ${ }^{54}$ Working in small teams, students improved their nutrition knowledge, as shown by a $41.1 \%$ increase in their posttest-nutrition measures when compared with corresponding pretest-measures. In addition, $92 \%$ $(n=27)$ of them expressed readiness to engage in team-based learning. The author suggested that nutrition was a unifying topicof-interest for achieving team-based competencies, and dyad-based or peer-peer learning also enhanced students' communication skills. ${ }^{54}$

When nutrition education served as a unifying topic-of-interest for IP students from different health professions, it augmented teambased learning and collaboration. The World Health Organization defined IP education as a group of students from two or more professions who learned about, from, and with each other to enable effective collaboration and improve health outcomes. ${ }^{55}$ Students are expected to become proficient in interprofessional education collaborative (IPEC) core competencies, such as appreciating one another's roles and responsibilities, developing IP communication skills, and working in teams. ${ }^{20}$ When nutrition education was offered to IP students as a unifying topic-of-interest, it enhanced their achievement of IPEC competencies. A prospective cohort of 119 medical and dietetic students at Ohio State University, in Columbus, $\mathrm{OH}$, took part in two 30-minute lecture interventions. ${ }^{56}$ The intervention included nutrition knowledge, nutrient pathophysiology, and techniques for dietary modification, using a team-based, problem-based approach. On completion of the intervention, students reported a significant increase in their confidence to offer healthy food solutions to patients and to recognize risk factors for nutrition-related diseases. Students from different health professions also appreciated each other's professional role in IP collaborative work. Medical students recognized the role of internship-experienced dietetic students as shown by a significant increase of 1.09 between their pretestposttest survey scores. Dietetic students felt their role in healthcare teams was recognized. This finding exemplified the importance of role and practice boundaries and the referral sources for more complex cases. Additionally, students developed camaraderie and gathered four times a year to explore other nutrition counseling techniques, highlighting the importance of providing adequate nutrition education that integrates the IPEC competencies in interprofessional health programs. ${ }^{56}$

Dental students and residents at Rutgers University in New Brunswick, NJ, who participated in a nutrition intervention improved their collaborative skills through IP learning. ${ }^{57}$ Under the guidance of dental and nutrition faculty, students worked in teams that reviewed patients' medical histories, physical findings, medications, and dietary supplements. The participants engaged in collaborative training and learned to appreciate the distinctive perspectives, knowledge, and skills that other disciplines brought to patient care. Students could describe potential interactions of medications and dietary supplements, interactions which could affect patients' nutrition, diet, and oral health. Furthermore, students improved their collaborative decision-making, problem-solving, and team-based communication. As teams, they solidified their ability to offer collective nutrition advice to patients during their clinical education rotations in the dental school clinics, as measured by the differences between their pre- and post-survey results. The authors asserted that nutrition could provide a common topic for students' collaboration across health professional programs. ${ }^{57}$

Fifty-four physician assistant and dental hygiene students at Eastern Washington University, WA, participated in a one-time workshop on oral manifestations of menopause, and as a team, managed a menopausal pseudo-standardized patient. On completion of the workshop, students improved their knowledge of menopause oral manifestations and nutrition risk factors, such as imbalanced diet and alcohol, caffeine, and salt consumption. ${ }^{45}$ Students also improved their perceptions regarding three IPEC 
competencies as demonstrated by significant increases in their pretest-posttest measures on Team and Collaboration, Roles and Responsibilities, and Interprofessional Communication. Qualitative data also demonstrated gained confidence in applying new skills to the oral manifestations of menopause. The authors suggested that implementation of IP nutrition education intervention improved not only nutrition knowledge and skills but also increased students' positive attitude toward IP education aimed to improve overall quality of patient life. 45

A group of 40 medical, physician assistant, social work, nursing, pharmacy, and internal medicine residents at Louisiana State University, LA, participated in a 2-semester intervention on diet and lifestyle modifications of patients with type-2 diabetes. ${ }^{58}$ Students worked as teams and coordinated care-management plans, while each learner had designated a profession-specific role to support each other. Nursing students performed screening and obtained patient HgA1c measures. Pharmacy students screened for alcohol use, calculated cardiovascular risks, and reviewed and assessed medication adherence. Medical students performed oral, foot, and eye exams, while physician assistant students performed similar duties of nursing and medical students. In parallel, social worker students performed depression screening and insurance status. Post intervention, students improved their appreciation for teamwork as indicated by a $25 \%$ increase of their posttest vs. pretest self-reports. Significant increases in patients' satisfaction for perceived quality of care $(27 \%)$ and students-patient communication (32\%) were also observed. The authors argued that there was a unidirectional linkage between student learning and care delivery in an IP nutrition-based care management. While students improved their knowledge and teamwork skills, patients reported on better diabetes control through implementing diet and lifestyle changes. 58

Both Touger-Decker and Peña-Purcell et al revealed a need for IP web-based nutrition courses in health professional programs. ${ }^{21,52}$ Interprofessional nutrition courses and core curriculum across health professional programs were reported as a means to surmount nutrition education limitations and to improve the communication skills of students across health professional programs. An IP nutrition course could also facilitate collaborations among faculty within a single program as well as faculty across several programs. ${ }^{52}$ This finding suggests that IP nutrition education might allow students to assist other students to accomplish the IPEC competencies, such as recognizing and respecting each other's professional role, enhancing IP communication, and promoting teamwork. Through appreciating each other's professions, students might learn to eliminate negative biases toward each other and respect colleagues of different ethnic and cultural backgrounds. Interprofessional nutrition education and collaborative teamwork might also promote students' communication skills and value the status of different health professionals. Together, the findings suggested that providing a standard unifying nutrition education for students across health professions will not only prepare them to engage in collaborative team-based practice but also may improve their nutrition knowledge, skills, and abilities to improve patients' health condition and outcomes.

Overall, a review of the literature on the need for nutrition education in health professional programs suggests that future efforts should focus on conducting need assessments in nutrition education across health professional programs. New directions for research and practice are inherently cross-cutting ideas for reforming nutrition education in the health professions and training students to become proactive, equal-based health professionals in providing improved patient-centered quality of care.

\section{CONCLUSIONS}

The ever-increasing burden of obesity and its nutrition-related diseases, together with health professionals' lack of nutrition competencies, emphasizes the pressing need to prepare all health professional students to appropriately counsel patients and the public on proper nutrition within the boundaries of their profession. Based on the studies reviewed, health professional students in certain situations may be lacking sufficient knowledge of basic nutrition and advising patients about healthy nutrition because of the inadequate nutrition education and training of these students. A review of the literature revealed deficiencies in the nutrition competencies of students in health professional programs. $22,23,29-31,40,42,44,46$ Students were deficient in basic nutrition knowledge and counseling skills and lacked confidence to offer basic nutrition education. Limitations of nutrition education across several programs were also reported. These included a limited number of nutrition hours integrated into a profession-specific curriculum, topics that should have been covered but were not, and poor communication skills. Several studies showed that nutrition intervention improved students' nutrition competencies significantly and increased their confidence in suggesting dietary advice. $39,45,54,56-58$ Nutrition was perceived as a unifying topic-of-interest across health professional programs for achieving IP teambased competencies intended to prepare students for future practice.

Interprofessional nutrition education was regarded as a means to surmount nutrition education limitations, such as improving students' communication skills across health professional programs and facilitating collaboration among faculty within and across programs. Interprofessional nutrition education also enhanced the achievement of IPEC competencies, such as appreciating one another's roles and responsibilities and developing IP communication and teamwork skills. Proficiency in IPEC along with improved nutrition knowledge will help students to deliver quality-of-care and improve patient outcomes in their practice, an assertion that 
was also supported by evidence. Indeed, the National Heart, Lung, and Blood Institute (NHLBI) has placed interprofessional nutrition education as a top research priority for improving coordinated care, the performance of all health professionals, and patient outcomes. ${ }^{59}$ Kushner et al suggested that IP teamwork across the continuum of health professions could address the nutrition needs of patients given shortages in the health workforce. ${ }^{60}$ This conclusion was further supported by Kahan and Manson. ${ }^{61}$ Interprofessional teamwork involves a group of health providers from different professions who work together, coordinate, and collaborate to deliver the highest quality of patient care, including nutrition education and nutrition counseling collectively. ${ }^{52}$ To that end, existing nutrition programs should fully close the gap between the prevalence of obesity and the shortage of health professionals as well as equip students with nutrition competencies.

Nutrition education in health professional programs should be revisited as it falls short of equipping students with essential nutrition competencies. This consequence might create conflicts and inconsistencies in the dietary messages conveyed by health professional students that could be linked to inadequate nutrition training. ${ }^{45}$ Insufficient nutrition counseling skills also created in students negative attitudes towards nutrition and lack of self-confidence, both of which worsened their nutrition deficiencies. ${ }^{25}$ Finally, nutrition education is also needed to better prepare health professional students to advise adults and particularly women regarding healthy nutrition to reduce the risk of obesity in future generations. Together, the growing indications of the inadequacy of nutrition education emphasize the need for more nutrition training of health professional students for prevention and management of chronic diseases. ${ }^{23,25}$ As a unifying topic-of-interest, a standard of nutrition education knowledge, skills, and abilities should focus on training students to both tackle nutrition-related risk factors like obesity and prevent or remedy prevalent nutrition-related diseases. $13,44,56$

\section{RECOMMENDATIONS}

As a preliminary literature review, this article contributes to the body of knowledge related to nutrition education in health professional programs and possibly provides the foundation for evidence-based research in nutrition education and interprofessionalism. Accordingly, the following recommendations for future research and practice are proposed:

1. Conduct a large-scale, national survey of faculty across health professional programs to determine the number of hours dedicated to nutrition education, the amount of specific nutrition content covered, nutrition topics that have not been covered, and activities surrounding nutrition education in their programs. This information could establish the groundwork for reforming nutrition education in health professional programs.

2. Explore the attitudes of health professional faculty toward nutrition education and determine whether these attitudes affect the quality of nutrition education provided by their programs.

3. Assess the effectiveness of dedicated nutrition education versus integrated nutrition concepts in the curriculum of each program and across health professional curricula.

4. Form an interprofessional curricular group to identify the needed nutrition content for each and across health professional programs.

5. Conduct monthly seminars and workshops to increase the awareness of health professional faculty of the role that nutrition plays in disease prevention and management and their responsibility to become agents of change for their students. Faculty will be guided by nutrition and education experts to develop guidelines for reforming nutrition education within their programs and for aligning their programs with the accreditation requirements for nutrition.

6. Explore the possibility that nutrition could serve a common topic-of-interest around which interprofessional courses in health professional programs could be built. This recommendation could be examined by considering both the insights of faculty and the perceptions of students.

7. Investigate the perceived benefits and challenges of faculty related to developing and running an interprofessional nutrition course across health professional programs.

8. Develop and investigate the feasibility of an interprofessional nutrition course for health professional programs. Increase the number of experiential learning opportunities for training health professional students in nutrition, in each of IPEC competencies and in team-based clinical settings. These opportunities will strengthen students' understanding of the vital role of nutrition in the diagnosis, treatment, and prevention of chronic diseases.

9. Finally, all health professional students should learn a common nutrition-based terminology and gain nutrition competencies so that they will be able to collaboratively combat and prevent the increasing prevalence of nutrition-related diseases. 


\section{REFERENCES}

1. Hales CM, Caroll MD, Fryar CD, Ogden CL. Prevalence of Obesity Among Adults and Youth: United States, 2015-2016. https://www.cdc.gov/nchs/data/databriefs/db288.pdf. Updated on October 2017. Accessed December 8, 2017.

2. Centers for Disease Control and Prevention. About Adult BMI. 2016.

https://www.cdc.gov/healthyweight/assessing/bmi/adult_bmi/ Updated on August 29, 2017. Accessed December 8, 2017.

3. National Center for Health Statistics. Obesity and Overweight. http://www.cdc.gov/nchs/fastats/obesity-overweight.htm Updated on June 13, 2016. Accessed December 8, 2017.

4. World Health Organization [WHO]. Global Strategy on Diet, Physical Activity and Health. http://www.who.int/dietphysicalactivity/publications/trs916/summary/en/. Updated on Feb 1, 2002. Accessed June 18, 2018.

5. Pi-Sunyer X. The medical risks of obesity. Postgrad Med. 2009;12(6):21-33. [PMID: 19940414].

6. Menke A, Casagrande S, Geiss L, Cowie CC. Prevalence of and trends in diabetes among adults in the United States, 19882012. JAMA. 2015;314(4):1021-9. [PMID: 26348752].

7. International Agency for Research on Cancer. Weight control and physical activity. In: Vainio H, Bianchini F, eds. International Agency for Research on Cancer. Lyon, France: International Agency for Research on Cancer Press; 2002:1-315.

8. Beck TJ, Petit MA, Wu G, LeBoff MS, Cauley JA, Chen Z. Does obesity really make the femur stronger? BMD, geometry, and fracture incidence in the women's health initiative-observational study. J Bone Miner Res. 2009;24(8):1369-79.

9. Delli Bivi AP, Di Muchele L, Laino G, Vajro P. Obesity and obesity related diseases, sugar consumption, and bad oral health: A fatal epidemic mixture. Trans/ Med UniSa. 2017;16(2):11-6. https://www.ncbi.nlm.nih.gov/pmc/articles/PMC5536157/pdf/tm-1611.pdf. Accessed on May 29, 2018.

10. Centers for Disease Control and Prevention. Chronic Disease Overview. https://www.cdc.gov/chronicdisease/overview/index.htm. Updated on June 28, 2017. Accessed December 8, 2017.

11. Gerteis J, Izrael D, Deitz D, LeRoy L, Ricciardi R., et al. Multiple Chronic Conditions Chartbook. AHRQ Publications No, Q140038. Rockville, MD: Agency for Healthcare Research and Quality; 2014.

12. Robert Wood Johnson Foundation. The Healthcare Cost of Obesity. https://stateofobesity.org/healthcare-costs-obesity/. Accessed December 8, 2017.

13. Dietz WH, Baur LA, Puhl RM, Taveras EM, Uauy R, Kopelman P. Management of obesity: Improvement of health-care training and systems for prevention and care. Lancet. 2015;385(9986):2521-33. [PMID: 25703112].

14. Bergerson N, Al-Saiegh S, Ip EJ. An analysis of California pharmacy and medical students' dietary and lifestyle practices. $A m \mathrm{~J}$ Pharm Educ. 2017;81(8):56-64. [PMID: 29200450].

15. Schoettler CL, Lee JN, Ireland KA, Lenders CM. A novel method of increasing medical student nutrition awareness and education. J Biomed Educ. 2015;Article ID 784042. https://www.hindawi.com/journals/ibe/2015/784042/. Accessed December 10, 2017.

16. Sacks GS. The shrinking of formalized nutrition education in health professions curricula and post-graduate training. JPEN J Parenter Enteral Nutr. 2017;41(2):217-25. [PMID: 28058977].

17. National Research Council, Committee on Nutrition in Medical Education. Nutrition Education in U.S. Medical Schools. Washington, DC: National Academies Press; 1985.

18. Weiner RL, Boker JR, Brooks CM, Kusher RF, Visek WJ, et al. Priorities for nutrition content in a medical school curriculum: a national consensus of medical educators. Am J Clin Nutr. 1989;50(4):707-12. [PMID: 2801575].

19. Moriates C, Dohan D, Spetz J, Sawaya FG. Defining competencies for education in health care value: Recommendations from the University of California, San Francisco Center for Healthcare Value Training Initiative. Acad Med. 2015;90(4):4214. [PMID: 25354077].

20. Interprofessional Education Collaborative Expert Panel. Core Competencies for Interprofessional Collaborative Practice: Report of an Expert Panel. Washington, D.C.: Interprofessional Education Collaborative. www.aacn.nche.edu/educationresources/IPECReport.pdf. Updated on May 2011. Accessed on November 15, 2016.

21. Touger-Decker R. Nutrition education of medical and dental students: Innovation through curriculum integration. Am J Clin Nutr. 2004;79(2):198-203. [PMID: 14719223].

22. Chang L, Popovich NG, Iramaneerat C, Smith EV, Lutfiyya MN. A clinical nutrition course to improve pharmacy students' skills and confidence in counseling patients. Am J Pharm Educ. 2008;72(3):Article 66.

https://www.ncbi.nlm.nih.gov/pmc/articles/PMC2508727/pdf/ajpe66.pdf. Accessed December 10, 2017.

23. Thomas DT, McArthur L, Corbett RW. Nutrition knowledge and attitudes of allied health and fitness students. J Allied Health. 2006:35(1):e-37-58. [PMID: 19759962].

24. Bezner JR. Promoting health and wellness: Implications for physical therapist practice. Phys Ther. 2015;95(10):1433-4. https://doi.org/10.2522/pti.20140271. Accessed May 23, 2018. [PMID: 25908523]. 
25. Greiner AC, Knebel E. Health professions education: A bridge to quality. Institute of Medicine, Washington, DC: National Academies Press;2003. http://www.iom.edu/Reports/2003/Health-Professions-Education-A-Bridge-to-Quality.aspx. Accessed December 24, 2017.

26. Ball L, Hughes R, Leveritt M. Health professional views of the effectiveness of nutrition care in general practice setting. Nutr Diet. 2013;70:35-41. http://onlinelibrary.wiley.com/doi/10.1111/j.1747-0080.2012.01627.x/abstract. Accessed December 9, 2017.

27. Ong HH, Wan CCJ, Gao X. Interprofessional collaboration in addressing diet as a common risk factor: A qualitative study. $J$ Res Interprof Pract Educ. 2015;5(2):215-26. http://www.jripe.org/index.php/journal/article/view/215/123. Accessed January 4, 2018.

28. DiMaria-Ghalili RA, Tobin BW, Hark L, Van Horn L, Palmer CA. Challenges and opportunities for nutrition education and training in the health care professions: Intraprofessional and interprofessional call to action. Am J Clin Nutr. 2014;99(5):1184S93S. [PMID: 24646823].

29. Favia M, Moore A, Kelly P, Werner C. What do physician assistant students know about nutrition? A survey of attitudes, self-perceived proficiency, and knowledge during three stages of physical assistant education. J Physician Assist Educ. 2016;27(3):131-5. [PMID: 27490290].

30. Touger-Decker R, Benedict-Barracato JM, O'Sullivan-Maillet J. Nutrition education in health profession programs: A survey of dental, physician assistant, nurse practitioner, and nurse midwifery programs. J Am Diet Assoc. 2001;101(1):63-9. [PMID: 11209587].

31. Demory-Luce DK, McPherson RS. Nutrition knowledge and attitudes of physician assistants. Clin Nutr. 1999;14(2):71-82. https://journals.Iww.com/topicsinclinicalnutrition/Abstract/1999/03000/Nutrition_Knowledge_and_Attitudes_of_Physician.9.aspx Accessed on October, 4, 2018.

32. Accreditation Review Commission on Education for the Physician Assistant. Accreditation standards for physician assistant education, 4e. Johns Creek, GA; 2017, p19.

33. American Physical Therapist Association. Nutrition and Physical Therapy. http://www.apta.org/PatientCare/Nutrition/. Updated on May 17, 2018. Accessed October 4, 2018.

34. Lehmann C. Nutrition: A portion of physical therapists' menu of services. PT in Motion. 2017;9(8):26-31. http://www.apta.org/PatientCare/Nutrition/. Updated on November 17, 2017. Accessed December 9, 2017.

35. Morris DM, Kitchin EM, Clark DE. Strategies for optimizing nutrition and weight reduction in physical therapy practice: The evidence. Physiother Theory Pract. 2009;25(5-6):408-23. [PMID: 19842865].

36. Nelson LV, Smith BS, Hunter AP. Nutrition knowledge of acute care physical therapists. Top Clin Nutr. 1997;12(3):33-41. http://journals.Iww.com/topicsinclinicalnutrition/Citation/1997/12030/Nutrition_Knowledge_of_Acute_Care_Physical.7.aspx. Accessed January 2, 2018.

37. Commission on accreditation in physical therapy education. Physical Therapy Standards and Required Elements. http://www.capteonline.org/uploadedFiles/CAPTEorg/About_CAPTE/Resources/Accreditation Handbook/CAPTE_PTStandards Evidence.pdf. Updated on July, 2017. Accessed May 23, 2018.

38. McClinchy J, Williams J, Gordo, L, Cairn M, Fairey G. Dietary advice and collaborative cooking: Do pharmacists and allied health professions other than dietitians have a role? Healthcare. 2015;3:64-77. https://www.mdpi.com/2227-9032/3/1/64. Accessed May 2, 2018.

39. Kotecki JE, Clayton BD. Educating pharmacy students about nutrition and physical activity counseling. $J$ Health Educ. 2003;34(1):34-40. https://files.eric.ed.gov/fulltext/EJ852391.pdf. Accessed December 5, 2017.

40. Antworth $A$, Maffeo $C$. Pharmacy student self-perception of weight and relationship to counseling patients on lifestyle modification. Am J Pharm Edu. 2014;78(2):Article 53,1-6. https://doi.org/10.5688/aipe78235. Accessed May 23, 2018.

41. Accreditation Council for Pharmacy Education. Accreditation Standards and Key Elements for the Professional Program in Pharmacy Leading to a Doctor of Pharmacy Degree. https://www.acpe-accredit.org/pdf/Standards2016FINAL.pdf. Updated on February, 2015. Accessed May 23, 2018.

42. Carney TA. Knowledge, Comfort Level, and Perceived Role of Nurses in Promoting Nutritional Management of Diabetes. [master's thesis]. Philadelphia, PA: Drexel University College of Nursing and Health Professions;2010.

43. American Association of Colleges of Nursing. Essentials of Master's Education in nursing. https://www.tnecampus.org/sites/default/files/docs and_pdfs/Masters\%20Essentials.pdf. Updated on March 21, 2011. Accessed May 23, 2018.

44. Shah K, Hunter ML, Fairchild RM, Morgan MZ. A comparison of nutrition knowledge of dental, dietetic and nutrition students. $\mathrm{Br}$ Dent J. 2011;210(1):33-8. [PMID: 212177728].

45. Rothmund WL, O'Kelley-Wetmore AD, Jones ML, Smith MB. Oral manifestation of menopause: An interprofessional intervention for dental hygiene and physician assistant students. JDH. 2017;(91(6):2121-32. [PMID: 29378803]. 
46. Huang ST, Chiou CC, Liu HY. Risk factors of aspiration pneumonia related to improper oral hygiene behavior in community dysphagia persons with nasogastric tube feeding. J Dent Sci. 2017;12(4):375-81. https://doi.org/10.1016/j.jds.2017.06.001 Access on May, 29, 2018.

47. Commission on Dental Accreditation. Accreditation Standards for Advanced Education Programs in General Dentistry. http://www.ada.org/ /media/CODA/Files/2017_aegd.pdf?la=en Updated on 2017. Accessed on May 25, 2018.

48. Malone M, Alger-Mayer SA. Pharmacist intervention enhances adherence to orlistat therapy. Ann Pharmacother. 2003;37(11):1598-602. [PMID: 14565841).

49. Jordan MA, Harmon J. Pharmacist interventions for obesity: Improving treatment adherence and patient outcomes. Integr Pharm Res Pract. 2015;4:79-89. [PMID: 29354522].

50. Marples $\mathrm{O}$, Baldwin $\mathrm{C}$, Weekes $\mathrm{E}$. The effect of nutrition training for health care staff on learner and patient outcomes in adults: A systematic review and meta-analysis. Am J Clin Nutr. 2017;106(1):284-310. [PMID: 28539379].

51. Machen RR, Hammer D, Odegard P. Elective course in nutrition taught by a pharmacy student. Am J Pharm Educ. 2007;71(1):Article 65,1-7. https://www.ncbi.nlm.nih.gov/pmc/articles/PMC1959205/pdf/aipe65.pdf. Accessed December 11, 2017.

52. Peña-Purcell N, Bowen E, Zoumenou V, Zoumenou V, Schuster ER, et al. Extension professionals' strengths and needs related to nutrition and health programs. JOE. 2012;50(3):Article 3RIB2. https://eric.ed.gov/?id=EJ1042553. Accessed February 12, 2018.

53. Lenders CM, Deen DD, Bistrian B, Edwards MS, Seidner DL, et al. Residency and specialties training in nutrition: A call for action. Am J Clin Nutr. 2014;99(5):1174S-83S. http://ajcn.nutrition.org/content/99/5/1174S.full.pdf+html Accessed January 25, 2018.

54. Pogge E. Evaluation of an interprofessional team-based learning nutrition and lifestyle modification course. J Interprof Care. 2016;30(2);248-50. [PMID: 26934200].

55. World Health Organization [WHO]. Framework for Action on Interprofessional Education and Collaborative Practice. Geneva: World Health Organization; 2010.

56. Cherian A, Gupta S, Habash D, Nahikiian-Nelms M, Pfeil S. Interprofessional education between medical and dietetic students: Prescribing medical nutrition therapy. Med Ed Publish. 2016. https://www.mededpublish.org/manuscripts/438/v1 Accessed February 10, 2018.

57. Ziehler J, Spivack E, Heir G, Rigassio-Radler D, Touger-Decker R. Interprofessional clinical training of nutrition and dental students/residents: Examining drug-nutrient/dietary supplement interactions and their impact on diet/nutrition and oral health. FASEB J. 2016;30(1):675-85. http://www.fasebj.org/content/30/1_Supplement/675.14.short Accessed December 10, 2017.

58. Coleman MT, McLean A, Williams L, Hasen K. Improvement in interprofessional student learning and patient outcomes. JIEP. 2017;8:28-33. https://www.jieponline.com/article/S2405-4526(16)30183-5/pdf Accessed on May 29, 2018.

59. National Heart, Lung, and Blood Institute [NHLBI]. Nutrition Education for Health Professionals. https://www.nhlbi.nih.gov/research/reports/2012-nutrition. Updated on 2012. Accessed December 8, 2017.

60. Kushner RF, Van Horn L, Rock CL, Edwars MS, Bales CW, et al. Nutrition education in medical school: A time of opportunity. Am J Clinl Nutr. 2014;99(5):1167S-73S. [PMID: 24646826].

61. Kahan S, Manson JE. Nutrition counseling in clinical practice: How clinicians can do better. JAMA. 2017;318(12):1101-2. [PMID: 28880975].

\section{Conflict of Interest}

The author certifies that she has no affiliations with or involvement in any organization or entity with any financial interest, or nonfinancial interest (such as personal or professional relationships, affiliations, knowledge, or beliefs) in the subject matter or materials discussed in this manuscript. 